\title{
Comparing Online and Face-to-Face Student Counselling: What Therapeutic Goals Are Identified and What Are the Implications for Educational Providers?
}

\author{
Terry Hanley, ${ }^{1}$ Zehra Ersahin, ${ }^{2}$ Aaron Sefi ${ }^{3}$ and Judith Hebron ${ }^{4}$ \\ 1 University of Manchester, United Kingdom \\ 2 Social Sciences University of Ankara, Turkey \\ 3 XenZone, Manchester, United Kingdom \\ 4 Leeds Trinity University, UK
}

\begin{abstract}
Online counselling is increasingly being used as an alternative to face-to-face student counselling. Using an exploratory mixed methods design, this project investigated the practice by examining the types of therapeutic goals that 11 to 25 -year-olds identify online in routine practice. These goals were then compared to goals identified in equivalent school and community-based counselling services; 1,137 online goals (expressed by 504 young people) and 221 face-toface goals (expressed by 220 young people) were analysed for key themes using grounded theory techniques. This analysis identified three core categories: (1) Intrapersonal Goals, (2) Interpersonal Goals, and (3) Intrapersonal Goals Directly Related to Others. Further statistical analysis of these themes indicated that online and face-to-face services appear to be used in different ways by students. These differences are discussed alongside the implications for professionals working in educational settings.
\end{abstract}

- Keywords: adolescents, online counselling, school-based counselling, youth counselling, goal-oriented therapy, help-seeking behaviours

\section{Background}

This project was completed in conjunction with Kooth, a counselling and support service for 11- to 25-year-olds in the United Kingdom. It has been widely involved in the development of services that are easy to access and youth friendly. As such, it provides anonymous online counselling using a single point of access via a website (www.kooth.com) and face-to-face counselling within secondary schools and 
community settings. All services are funded by external partners, such as Local Authorities and the National Health Service's Clinical Commissioning Groups, and are free at the point of delivery. The counselling offered by the Kooth service is pluralistic (Cooper \& McLeod, 2011) and explicitly focused upon the goals that the individuals accessing therapy identify alongside their counsellors. Below we outline how the literature related to the context of the service and this goal-oriented approach feed into the aims of this study.

\section{Developing Accessible Counselling for Students}

Young people and young adults are highlighted as a group that are at risk of psychological distress (e.g., Coleman \& Brooks, 2009). As education providers commonly have substantial contact with individuals during this life stage, they are increasingly recognised as having the potential to become hubs for offering whole-school and targeted social and emotional support (Department of Health, 2015). Such interventions have been linked to improvements in students' social and emotional competence, academic attainment and ability to engage with learning, improvements in behaviour, and the reduction of mental health problems more generally (Department of Education, 2015; Durlak, Weissberg, Dymnicki, Taylor, \& Schellinger, 2011). As a consequence, educational providers can be seen to be routinely funding mental health services through their own budgets (e.g., Hanley, Jenkins, Barlow, Humphrey, \& Wigelsworth, 2013), and the development of appropriate and accessible targeted services, such as counselling, has become a major consideration for schools (e.g., Harris, 2013).

When seeking psychological support, young people and young adults appear to look increasingly towards the internet (Gray, Klein, Noyce, Sesselberg, \& Cantrill, 2005). In response to this growing need, online counselling services have begun to develop with the hope of further increasing the accessibility of therapeutic services (Pattison, Hanley, Pykhtina, \& Ersahin, 2015). Notably, such services have emerged throughout the world - for example, in Africa: Pattison, Hanley and Sefi (2012); Australia: Glasheen and Campbell (2009); and Europe: Vossler and Hanley (2010). These services have been created to respond to national contexts and have been used in conjunction with, and as an alternative to, traditional face-to-face delivery (e.g., school-based counselling services). Interestingly, where counselling has been accessed by young people outside traditional healthcare settings (e.g., within schoolbased counselling), it is notable that the severity of presenting issues does not appear to vary (Cooper, 2013). There is even some indication that online presentations may be more complex than some face-to-face settings (Sefi \& Hanley, 2012).

Benefits are reported for those both accessing and providing online counselling services. Young users report that they find the online environment safe and feel less exposed, confronted and stigmatised (e.g., Hanley, 2012; King, Bambling, Lloyd, et al., 2006). Therefore, the anonymity of online counselling helps to ease the discomfort of making what can be perceived as embarrassing disclosures. Further, the increased ability and freedom to access such services is also suggested to enhance client autonomy in the therapeutic relationship, thus empowering the young person in the therapeutic dyad (Gibson \& Cartwright, 2013; Hanley, 2012). Counsellors express similar positive sentiments. Specifically, they report that therapeutic relationships can be more convenient and feel safer when working online with young 
people (e.g., Bambling, King, Reid, \& Wegner, 2008; Dowling \& Rickwood, 2016; Glasheen, Campbell, \& Shochet, 2013).

In contrast to the benefits, challenges related to online practice with this group are also reported within the literature. For instance, practical concerns are noted around the infrastructure needed for such practice (Callahan \& Inckle, 2012; Hanley, 2006) and the delivery of effective therapeutic interventions are also raised. In relation to the latter, King, Bambling, Reid, and Thomas (2006) and King, Bambling, Lloyd et al. (2006) report user concerns over the counsellor's ability to grasp their feelings (and vice versa), the limited exchange time in text format within the time constraints, and the loss of immediacy in online practices. Therefore, although online counselling for young people is still an emerging field, it is an arena that is growing at pace and in need of further consideration.

\section{Goal-Oriented Therapy}

Therapy that is oriented towards the goals of young people is increasingly being advocated by psychologists (e.g., Hanley, Williams, \& Sefi, 2013). Therapeutic goals have been described as the 'internal representations of desired states' (Austin \& Vancouver, 1996, p. 338). Therapeutic approaches that advocate the articulation of goals from clients often base this approach within existential philosophies that place emphasis on the purposeful and future-oriented nature of the human (e.g. Cooper, 2015; Hanley, Sefi, \& Ersahin, 2016). This position commonly aligns itself to the holistic stance of humanistic psychology (e.g., Bugental, 1964) and views clients as active agents within the therapeutic process (Bohart, 2000; also see Gibson \& Cartwright, 2013 for a discussion of agency in therapy with young people). Furthermore, within psychological literature, the focus upon goals in therapy has particularly gathered momentum in the concept of the therapeutic alliance (as first described by Arbor \& Bordin, 1979). Within this conceptualisation, goals are viewed alongside the therapeutic bond and tasks as key common factors of the therapeutic relationship. The alliance has received much attention in the therapeutic research literature and has been identified as a major contributor to successful therapeutic outcomes for both adult (Horvath, Del Re, Flückiger, \& Symonds, 2011) and adolescent populations (Shirk, Karver, \& Brown, 2011).

The goals with which individuals approach therapy are incredibly varied. A variety of taxonomies have been developed to categorise these. For instance, the Bern inventory (Grosse \& Grawe, 2002) summarises 1,031 goals articulated by 298 outpatients at a university clinic into five different categories: (1) coping with specific problems and symptoms, (2) interpersonal goals, (3) wellbeing and functioning, (4) existential issues, and (5) personal growth. Similarly, Rupani et al. (2013) explored 199 goals expressed by 73 young people who had accessed school-based counselling. These findings revealed that the goals fell into four major domains: (1) emotional goals, (2) interpersonal goals, (3) goals targeting specific issues, and (4) personal growth goals. As is evident within these two classification systems, taxonomies vary in their degrees of divergence and convergence.

Goal-oriented therapy refers to therapeutic practice in which interventions are focused around the specific goals that have been articulated by the client (or clients). As with the therapeutic alliance, the consensus between the goal of the therapist and client is an element of the therapeutic relationship that meta-analyses report to have 
a positive effect upon the therapeutic outcome (Tryon \& Winograd, 2011). With such sentiments in mind, therapeutic approaches, such as Cooper and McLeod's pluralistic framework for counselling and psychotherapy (2011), have been specifically devised to harness the potential positive components of such a process. As well as being utilised in adult populations, the pluralistic framework has also been suggested for therapeutic work with young people (Hanley, Williams et al., 2013). Within this framework, goal articulation is viewed as an ethically minded position supporting the client to be actively involved in helping to orchestrate the therapeutic process (Hanley et al., 2016).

\section{Rationale}

As online therapeutic work becomes more commonplace for student populations, further examination of the type of work being undertaken is much needed. This project therefore provides a significant exploration of the field by examining collaboratively developed therapy goals that are expressed in counselling sessions. Such investigation will help professionals to further understand not only the reasons why young people seek support online, but also to gain a sense of the impact of new technologies upon the types of goals that individuals seek to address in therapy. Identifying such factors will prove helpful to service providers, such as in educational settings, when considering whether to invest in such provision. With this in mind, the following research questions were formulated for the study.

1. What type of goals do young people identify as working towards during online and face-to-face therapy?

2. How do the goals that young people articulate online and face to face compare?

3. Based upon the goals identified, how might online counselling services have an impact upon professionals working in educational settings?

\section{Methodology}

This study utilised an exploratory mixed methods research design (Creswell, Plano Clark, Gutmann, \& Hanson, 2003). Initially a qualitative approach (grounded theory) was taken to make sense of the wide variety of goals that had been articulated during the counselling sessions. Following this, statistical analysis (inferential and descriptive) was used to compare the prevalence of the different types of goals that were reported in online and face-to-face settings.

\section{Data Collection: Procedure, Participants, and Ethical Considerations}

The project involved collating the therapy goals of 11 - to 25 -year-olds who used the Kooth counselling services. All the data considered here were routinely collected by the therapy services. Goals were formed collaboratively with counsellors at the outset of counselling (or during regular review periods) using the organisation's Counselling Goal System (CoGS). A version of the CoGS was embedded within the online system and a paper version used with face-to-face clients (see Appendix for a blank version of the form used in face-to-face work). This encourages clients to briefly articulate goals for counselling (e.g., 'To explore why I feel people don't like me') and enables achievement of goals to be reviewed quantitatively (regularly 
asking clients to rate whether they have been met since their last meeting). The counsellors working for the service were originally trained in a range of therapeutic approaches. All had received training in the process of supporting young people to articulate their goals for counselling, and those working online had also received training to work in this medium.

The counselling was delivered either online (using the online access point www.kooth.com) or face to face within a school or community setting. Although confirmation of the service user's location is required for the online service, no personally identifiable material is required for an individual to use it. This is in contrast to the face-to-face service where people are likely to have been referred by a member of the school staff. No record of the referrer was available at the time of analysis.

Within the online sample, 1,137 goals were collated from 504 young people during the time period December 2013 - July 2014 (74\% identified themselves as female, with the mean age being 16.5 (median 16, SD 2.76). During the same period, 221 goals were collated from 220 young people accessing face-to-face therapy $166 \%$ were from school-based provision and $34 \%$ from services based in the local community; $70 \%$ were female; and the mean age was 14 [median 14, SD 2.00]). The demographics of the service users here generally reflect the demographic make-up of the services more generally.

The research was approved by the University Research Ethics Committee associated with the lead author's place of work. It adhered to the Code of Human Research Ethics developed by the British Psychological Society (2010) as well as the ethical guidelines of the host organisation (Bond, 2004).

\section{Data Analysis}

Techniques from the grounded theory approach were used to analyse the goals that had been articulated by the young people for key themes (Charmaz, 2000). The inductive nature of the analysis meant that previous conceptualisations of goal taxonomies were not considered during the initial analysis stage. This naive stance was adopted so that the analysis would not be greatly influenced by the thinking of others and thus the analysis would be open to new themes (e.g., Rennie \& Fergus, 2006)

Common protocols associated with grounded theory were utilised to develop a hierarchy related to the data in question (Strauss \& Corbin, 1998). The goals that the young people reported ( $\mathrm{N}=1,358$ were divided into meaning units (MUs; see Rennie, Phillips, \& Quartaro, 1988) and coded into representing categories by two members of the research team. During this process, a number of the goals were divided up so as to account for their multifaceted nature (MUs ultimately totalling 1,469$)$. Once agreement was reached on the categorisation of these lower order codes, exploration of the commonalities led to the creation of higher order categories. This constant comparison across categories enabled the authors to reflect upon the internal consistency of the developing model (Maykut \& Morehouse, 1994). A third team member was utilised as a means of checking the coherence of the analysis and to mediate any disagreement between the core coders.

Once the qualitative data had been analysed for key themes, content analysis was used to reflect upon the differences that were evident within the online and faceto-face datasets (Krippendorff, 2013). Descriptive and inferential statistics were calculated for each layer of abstraction within the grounded theory analysis. A 
chi-square test for goodness of fit was then used with each of the core categories and subcategories to determine whether the differences in the proportion of goals were statistically significant. Where this was found to be the case, effect sizes were used calculated using Cohen's $\omega$ (Cohen, 1992). These figures then provide discussion points for comparisons to be made to the two modes of counselling being considered.

\section{Findings and Discussion}

To start this section, a summary of all of the goals that were articulated is provided. This involves presenting the three core categories that emerged alongside the subsequent lower order sets of subcategories. Following on from this, further analysis is provided that specifically reflects upon how the goals that were articulated differ in online work when compared to face-to-face work.

\section{Identifying Therapeutic Goals}

The goals individuals articulated at the beginning of counselling (both online and face-to-face) were conceptualised under three core categories, namely (1) Intrapersonal Goals, (2) Interpersonal Goals and (3) Intrapersonal Goals Directly Related to Others. The two former core categories, Intrapersonal Goals and Interpersonal Goals, resonate explicitly with other taxonomies of therapeutic goals related to work with young people and young adults (e.g. Bradley, Murphy, Fugard, Nolas, \& Law, 2013; Rupani et al., 2013). In between these areas however, there were a substantial number of goals that young people identified that did not fit neatly within these two core categories. This led to the creation of the third category, Intrapersonal Goals Directly Related to Others, to represent the types of goals in which individuals expressed the hope to work on intrapersonal goals that had a direct relationship to others (e.g., friends, family members or organisations). These goals contrast to those Intrapersonal Goals noted above that are solely articulated towards internal processes. Figure 1 outlines definitions of these three overarching core categories.

To provide further information of how each of these codes relate to one another, Table 1 provides a detailed account of the multiple levels of the coding process. This includes reference to the three overarching core categories, the subcategories identified, and the associated lower order properties (MUs). Illustrative examples of the goals that were articulated for each subcategory are also provided.

\section{Comparing Online Goals to Face-to-Face Goals}

The number of goals reported were converted to percentages and then compared using the chi-square test for goodness of fit. For the three core categories, only Intrapersonal Goals Directly Related to Others (Table 2) demonstrated a statistically significant difference between online and face-to-face goals, with a greater number emerging online. This difference may be attributable to the online setting in which individuals may utilise the internet as a first point of call for accessing support (e.g., Gray et al., 2005). For instance, a large number of the articulated goals related to making contact with other services (e.g., 'Speak to head of year about ...'). Thus, individuals may be using confidential services such as this as a 
TABLE 1

Full Breakdown of Goal Categorisation

\begin{tabular}{|c|c|c|c|}
\hline Core category & Subcategory & Meaning units & Illustrative goals \\
\hline Intrapersonal goals & Personal growth & Exploring thoughts and feelings & 'To explore why I feel people don't like me' \\
\hline Online $=760$ & Online $=350$ & Owning the problems & 'Wear short sleeves in public' \\
\hline $\mathrm{F} 2 \mathrm{~F}=208$ & $\mathrm{~F} 2 \mathrm{~F}=60$ & Improving confidence and self-esteem & 'Identify five things that I like about myself' \\
\hline \multirow[t]{17}{*}{ Total $=968$} & Total $=410$ & Developing skills & 'Acknowledge that it's okay to feel sad' \\
\hline & & Accepting self & 'It's okay to be myself' \\
\hline & Emotional wellbeing & Feel happier & 'Control emotions so not crying all the time' \\
\hline & Online $=124$ & Keep calm (less anxious) and regulate & 'To feel happy and more in control' \\
\hline & $\mathrm{F} 2 \mathrm{~F}=74$ & emotions & 'To manage my moods better' \\
\hline & Total $=198$ & $\begin{array}{l}\text { Work on anger, and grief (utilise alternative } \\
\text { ways to cope) } \\
\text { Enjoy self and treat }\end{array}$ & $\begin{array}{l}\text { 'I wanna be okay with my mind not let it control me' } \\
\text { 'Give permission myself for a shopping day with } \\
\text { mum' }\end{array}$ \\
\hline & Mental wellbeing & Explore (have a better factual understanding & 'Read information on physical symptoms of anxiety' \\
\hline & Online $=116$ & of the mental health problem — various) & 'To explore why I hurt myself' \\
\hline & $\mathrm{F} 2 \mathrm{~F}=35$ & Work on mental health issue (e.g. self-harm, & 'Write or draw feelings instead of self-harming' \\
\hline & Total $=151$ & $\begin{array}{l}\text { anxiety, depression, suicidal tendency, } \\
\text { eating difficulties, obsessive compulsive }\end{array}$ & $\begin{array}{l}\text { 'Practise safe place visualisation, and techniques to } \\
\text { control suicidal feelings' }\end{array}$ \\
\hline & & $\begin{array}{l}\text { disorder) by utilising a coping strategy } \\
\text { (mindfulness \& yoga, relaxation exercises, } \\
\text { narrative work) }\end{array}$ & 'Go for a walk to help lift depression' \\
\hline & Physical wellbeing & Self-care (e.g., sleep hygiene, stopping & 'Walk home from school for exercise' \\
\hline & Online $=87$ & smoking, having a healthy diet) & 'Wear underwear and longer skirts/ trousers to \\
\hline & $F 2 F=22$ & Exercising to keep fit & school' \\
\hline & Total $=109$ & Keep safe and sound (and alive) & 'Start jogging at weekends' \\
\hline & & & 'Drop a size from 12 to 10 by eating healthy' \\
\hline & & & 'To shower and dress every day' \\
\hline
\end{tabular}


TABLE 1

Continued

\begin{tabular}{llll}
\hline Core category & Subcategory & Meaning units & Illustrative goals \\
\hline & School/career & Aspirational (e.g., pursuing an interest at & 'Practice online resources one hour a day to pass the \\
& Online $=83$ & university, planning on a professional & RAF test'
\end{tabular}

university, planning on a professional

RAF test'

$\mathrm{F} 2 \mathrm{~F}=17$

career, be successful)

Total $=100$

Interpersonal goals

Online $=89$

$\mathrm{F} 2 \mathrm{~F}=25$

Total $=114$ good grades)

Improving relationships with family members

Online $=55$

$\mathrm{F} 2 \mathrm{~F}=6$
Exams (e.g., getting organised, getting

Total $=61$

Improving relationships with friends

Online $=19$

$\mathrm{F} 2 \mathrm{~F}=19$

Total $=38$

Improving intimate relationships

Online $=15$

$\mathrm{F} 2 \mathrm{~F}=0$

Total $=15$ relationship
'To succeed in school and get a job to secure herself' 'Become a good writer like John Green'

'I want to be in a band and tour the world' 'Complete my A Levels to get into the uni'

'Eat out with family'

'Improve relationships with family and friends' 'Get closer to brothers'

'Have a serious chat with mum this week'

'Go out with grandma'

'Talk to Harry about their friend Charlotte'

'Speak with friends about valuing their friendships'

'Have working-loving relationships'

'React differently to his friends' bullying'

'Make up with friend'

Improve relationship with intimate partner

'To have a better relation with girlfriend'

'Text boyfriend when phone is fixed'

'Talk to gf regarding his hurt feelings around her comments'

ain a greater understanding of intimate

'Let someone who he has strong feelings for know' 'Explore what would a meaningful relationship with 
TABLE 1

Continued

\begin{tabular}{|c|c|c|c|}
\hline Core category & Subcategory & Meaning units & Illustrative goals \\
\hline \multirow{3}{*}{$\begin{array}{l}\text { Intrapersonal goals } \\
\text { directly related to } \\
\text { others } \\
\text { Online }=357\end{array}$} & $\begin{array}{l}\text { Asking for help (and getting } \\
\text { help) }\end{array}$ & $\begin{array}{l}\text { Seeking health assessment (e.g., GP, nurse, } \\
\text { psychiatrist) }\end{array}$ & $\begin{array}{l}\text { 'To ring Brook for pregnancy test at clinic' } \\
\text { 'Speak to head of var about CAMH's referral again' }\end{array}$ \\
\hline & & \multirow{2}{*}{$\begin{array}{l}\text { Connecting to support network (e.g. family, } \\
\text { friends, teachers, tutors, pastoral care) }\end{array}$} & $\begin{array}{l}\text { 'Speak to head of year about CAIVIH's reterral again' } \\
\text { 'Transfer from Kooth to face-to-face counselling' }\end{array}$ \\
\hline & $\mathrm{F} 2 \mathrm{~F}=3$ & & 'Ask tutors for more support to improve their grade' \\
\hline $\mathrm{F} 2 \mathrm{~F}=30$ & Total $=158$ & Accessing F2F counselling services & 'Get through difficult day by coming online' \\
\hline \multirow[t]{16}{*}{ Total $=387$} & \multirow{2}{*}{$\begin{array}{l}\text { Getting out of comfort zone } \\
\text { (challenging behaviour) }\end{array}$} & Be resilient (against bullies/negative people) & 'Come back to chat next Monday, 8 pm' \\
\hline & & Be assertive in relationships & 'Stay off Facebook for few days until more settled' \\
\hline & Online $=51$ & Set boundaries & 'To learn to live with brother's Aspergers' \\
\hline & $\mathrm{F} 2 \mathrm{~F}=12$ & \multirow[t]{2}{*}{ Commit to therapy (therefore wellbeing) } & 'Stop saying sorry, change to respect' \\
\hline & Total $=63$ & & 'Practise to bat back insulting remarks' \\
\hline & $\begin{array}{l}\text { Speaking up (communicate } \\
\text { self better) }\end{array}$ & $\begin{array}{l}\text { Expressing self better and more open to } \\
\text { significant others }\end{array}$ & $\begin{array}{l}\text { 'Talk to friend about his hurt feelings' } \\
\text { 'To speak to the nurse and be more open with her' }\end{array}$ \\
\hline & Online $=94$ & \multirow[t]{3}{*}{ Get things off my chest } & 'Let someone know who he has strong feelings for' \\
\hline & $\mathrm{F} 2 \mathrm{~F}=15$ & & 'To talk things through and get them off my chest' \\
\hline & Total $=109$ & & 'Be open and honest with Kooth' \\
\hline & Fitting in (in relation to & Feel comfortable in relationships & 'Look after granma who has early dementia' \\
\hline & significant other) & To accept others and be accepted by others & 'To be comfortable making and keeping \\
\hline & Online $=57$ & \multirow[t]{5}{*}{ Attend to significant others' needs } & relationships' \\
\hline & $\mathrm{F} 2 \mathrm{~F}=0$ & & 'Succeed and be a good person to keep grandpa \\
\hline & \multirow[t]{3}{*}{ Total $=57$} & & proud' \\
\hline & & & 'Talk to people more without feeling embarrassed' \\
\hline & & & 'I want my parents to accept me being gay' \\
\hline
\end{tabular}

Note: $F 2 F=$ face to face. 


\section{TABLE 2}

Percentage Split of the Meaning Units Related to the Core Categories, Divided by Media

\begin{tabular}{|c|c|c|c|c|}
\hline \multirow[b]{2}{*}{ Core category } & \multirow{2}{*}{$\begin{array}{l}\% \text { of MUs } \\
\text { online }(N)\end{array}$} & \multirow{2}{*}{$\begin{array}{l}\% \text { of MUs } \\
\text { F2F }(N)\end{array}$} & \multicolumn{2}{|c|}{ Chi-square $(\chi 2)$ test for goodness of fit } \\
\hline & & & $\chi 2$ statistic & Cohen's $\omega \dagger$ \\
\hline Intrapersonal goals & $63.02 \%(760)$ & $79.09 \%(208)$ & $\chi 2=1.803, p=.179$ & N/A \\
\hline Interpersonal goals & $7.38 \%(89)$ & $10.50(25)$ & $\chi 2=.889, p=.346$ & N/A \\
\hline $\begin{array}{l}\text { Intrapersonal goals } \\
\text { related to others }\end{array}$ & $29.60 \%(357)$ & $11.41(30)$ & $\chi^{2}=8.805, p=.003$ & .21 (small) \\
\hline
\end{tabular}

Note: $\nmid$ Cohen's $\omega$ represents the effect size, where .2 is small, .3 is medium, and .5 or higher is large. MUs = meaning units. Significant findings in bold type.

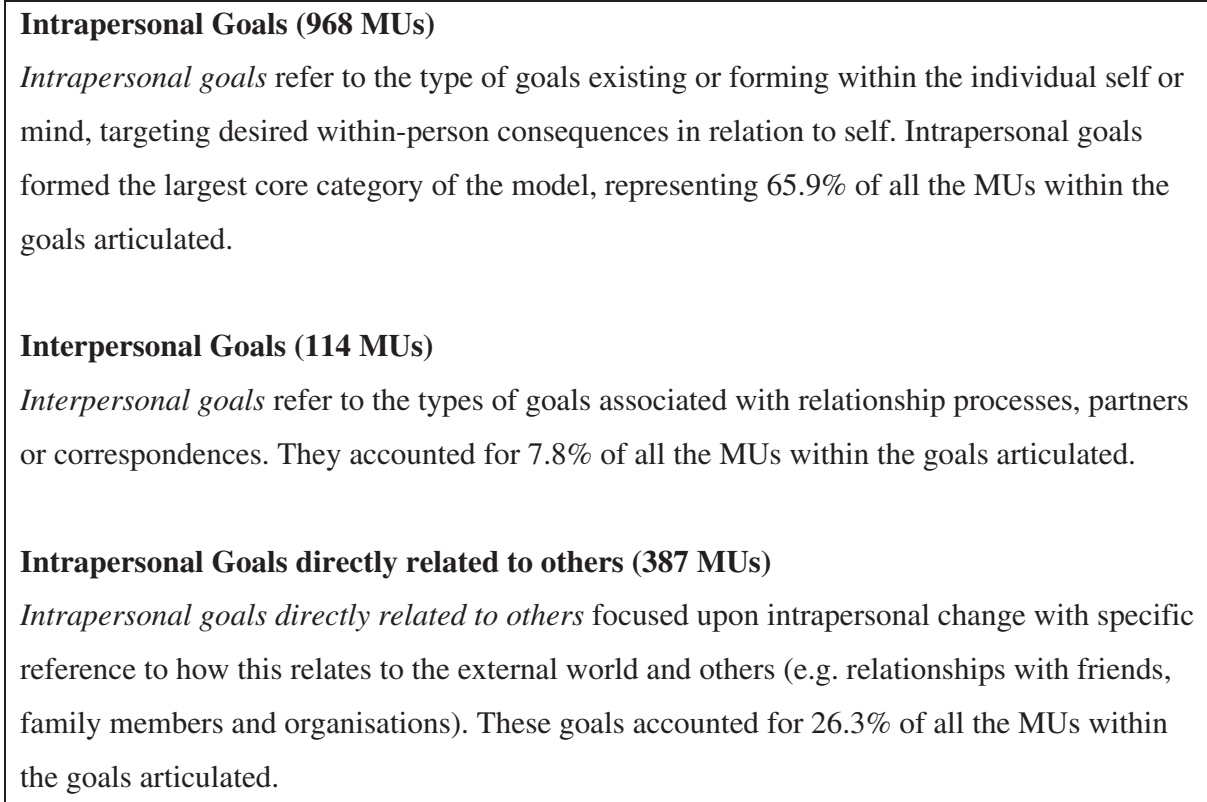

\section{FIGURE 1}

Definitions of the 3 Core Categories

means of 'psychological triage', being supported and gathering information related to further support. Such a process would also support the view that young clients are active agents involved in determining the therapeutic work in which they engage (Gibson \& Cartwright, 2013).

When analysing the goals according to subcategories and media, a greater number of differences were found. These are discussed in turn below and shown in Tables 3, 4, and 5, with statistically significant differences highlighted in bold text.

Within the Intrapersonal Goals core category the subcategories personal growth and emotional wellbeing differed significantly between the two media. Specifically, personal growth goals were predominant online while emotional wellbeing goals 


\section{TABLE 3}

Percentage Split of the MUs Related to the Intrapersonal Goals Core Category, Divided by Media

\begin{tabular}{|c|c|c|c|c|}
\hline \multirow{2}{*}{$\begin{array}{l}\text { Intrapersonal goals - } \\
\text { subcategories }\end{array}$} & \multirow{2}{*}{$\begin{array}{l}\% \text { of MUs } \\
\text { online }(N)\end{array}$} & \multirow{2}{*}{$\begin{array}{l}\% \text { of } M U s \\
F 2 F(N)\end{array}$} & \multicolumn{2}{|c|}{ Chi-square $(\chi 2)$ test for goodness of fit } \\
\hline & & & $\chi 2$ statistic & Cohen's $\omega \dagger$ \\
\hline 1a Personal growth & $46.05 \%(350)$ & $28.85 \%(60)$ & $\chi^{2}=3.853 . p=.05$ & .1387 (small) \\
\hline 1b Emotional wellbeing & $16.32 \%(124)$ & $35.58 \%(74)$ & $\chi 2=7.692, p=.006$ & .1961 (small) \\
\hline 1c Mental wellbeing & $15.26 \%(116)$ & $16.83(35)$ & $\chi 2=.125, p=.724$ & N/A \\
\hline 1d Physical wellbeing & $11.45 \%(87)$ & $10.57 \%(22)$ & $\chi^{2}=.000, p=1$ & N/A \\
\hline 1e School/career & $10.92 \%(83)$ & $8.17 \%(17)$ & $\chi^{2}=.474, p=.491$ & $\mathrm{~N} / \mathrm{A}$ \\
\hline
\end{tabular}

Note: $\mathrm{MUs}=$ meaning units. Significant findings in bold type.

\section{TABLE 4}

Percentage Split of Meaning Units Related to the Interpersonal Goals Core Category, Divided by Media

\begin{tabular}{|c|c|c|c|c|}
\hline \multirow{2}{*}{$\begin{array}{l}\text { Interpersonal goals - } \\
\text { subcategories }\end{array}$} & \multirow{2}{*}{$\begin{array}{l}\% \text { of MUs } \\
\text { Online }(N)\end{array}$} & \multirow{2}{*}{$\begin{array}{l}\% \text { of MUs } \\
\text { F2F }(N)\end{array}$} & \multicolumn{2}{|c|}{ Chi-square $(\chi 2)$ test for goodness of fit } \\
\hline & & & $\chi 2$ statistic & Cohen's $\omega \dagger$ \\
\hline $\begin{array}{l}\text { 3a Asking for help (and } \\
\text { getting help) }\end{array}$ & $43.42 \%(155)$ & $10.00 \%(3)$ & $\chi^{2}=20.547, p=.000$ & .3205 (medium) \\
\hline $\begin{array}{l}\text { 3b Speaking up } \\
\text { (communicate self better) }\end{array}$ & $26.33 \%(94)$ & $50.00 \%(15)$ & $\chi 2=7.579, p=.006$ & .1946 (small) \\
\hline $\begin{array}{l}\text { 3c Fitting in (in relation to } \\
\text { significant other) }\end{array}$ & $15.96 \%(57)$ & $0.00 \%(0)$ & N/A $\ddagger$ & N/A \\
\hline $\begin{array}{l}3 d \text { Getting out of comfort } \\
\text { zone (challenging } \\
\text { behaviour) }\end{array}$ & $14.29 \%(51)$ & $40.00 \%(12)$ & $\chi^{2}=12.519, p=.000$ & .2502 (small) \\
\hline
\end{tabular}

Note: $\ddagger$ Chi-square test for goodness of fit cannot be computed with values of less than 5 . However, in the two cases in this study, the likelihood is that there is a significant difference between the two media, as one value is $0 \%$ and the other is above $15 \%$. MUs = meaning units. Significant findings in bold type.

\section{TABLE 5}

Percentage Split of the Meaning Units Related to the Intrapersonal Goals Directly Related to Others Core Category, Divided by Media

\begin{tabular}{|c|c|c|c|c|}
\hline \multirow{2}{*}{$\begin{array}{l}\text { Intrapersonal goals } \\
\text { directly relating to others } \\
\text { — subcategories }\end{array}$} & \multirow{2}{*}{$\begin{array}{l}\% \text { of } M U s \\
\text { Online }(N)\end{array}$} & \multirow{2}{*}{$\begin{array}{l}\% \text { of MUs } \\
\text { F2F }(N)\end{array}$} & \multicolumn{2}{|c|}{ Chi-square $(\chi 2)$ test for goodness of fit } \\
\hline & & & $\chi 2$ statistic & Cohen's $\omega \dagger$ \\
\hline $\begin{array}{l}\text { 2a Improving relationships } \\
\text { with friends }\end{array}$ & $61.80 \%(55)$ & $24.00 \%(6)$ & $\chi^{2}=16.791, p=.000$ & .2897 (medium) \\
\hline $\begin{array}{l}2 b \text { Improving relationships } \\
\text { with family }\end{array}$ & $21.35 \%(19)$ & $76.00 \%(19)$ & $\chi 2=31.186, p=.000$ & .3948 (medium) \\
\hline $\begin{array}{l}\text { 2c Improving intimate } \\
\text { relationships }\end{array}$ & $16.85 \%(15)$ & $0.00 \%(0)$ & N/A $\ddagger$ & N/A \\
\hline
\end{tabular}

Note: MUs = meaning units. Significant findings in bold type. 
were more prevalent face to face. The former may reflect the more explorative and slower paced nature of therapeutic work that is reported online (King, Bambling, Reid, et al., 2006), while the larger number of emotional wellbeing goals face to face is more difficult to explain without additional investigation. Further, both the online and face-to-face groups identified intrapersonal goals related to school/career (e.g. 'to succeed in school and get a job to secure herself') as the smallest category represented. This latter element indicates that for many of the young people in this sample, issues directly related to school are not the primary motivation for seeking support. Thus, as reported in other studies, the benefits of counselling upon educational attainment are more likely to be as a consequence of support more broadly (Rupani, Haughey, \& Cooper, 2012).

The greatest difference between the online and face-to-face groupings was noted within the Interpersonal Goals category. A majority of the issues presented online related to improving relationships with friends, while face to face this was improving relationships with family. Interpretations could relate to the perceived expectations that a young person might have about the therapeutic process or be related to the priorities of referring individuals. Further investigation is clearly warranted here to gain insight into help-seeking behaviours related to this group. Additionally, it is evident that no goals related to intimate relationships were articulated face to face compared to $16.9 \%$ online. Such findings, although not representative of the whole content of therapy sessions, may reflect the heightened safety that young people perceive within a more anonymous environment (Gibson \& Cartwright, 2013); a factor that may be linked to the disinhibition effect that is commonly discussed in relation to online communication (e.g., Suler, 2004).

Within the Intrapersonal Goals Directly Related to Others core category, differences are notable. No codes related to the fitting in subcategory were identified within the face-to-face sample (in contrast to $16 \%$ of the responses online), and the primary goal online related to asking for help (and getting help); $43.4 \%$ reflecting a medium-effect size when contrasted to the face-to-face goals. Speaking up and getting out of comfort zone both indicated small effect sizes in favour of the face-to-face grouping. As is mentioned above, such a phenomenon may be related to young people's help-seeking behaviour patterns (Gray et al., 2005). They also demonstrate that the internet can act as a mediator for connecting, rather than escaping from support (Wolak, Mitchell, \& Finkelhor, 2003) and that it might be perceived as a safer more comfortable space for some individuals (a factor that can be viewed both positively and negatively). Given the proactive nature expressed in these goals, such a process might also echo the findings of research in which young people positively report a shift in power from counsellor to client (Gibson \& Cartwright, 2013; Hanley, 2012).

These points, although not making broad claims of representativeness, provide numerous arenas to complement and further our understanding of the ways in which students utilise online counselling services in contrast to face-to-face services.

\section{Implications for Educational Providers}

The third question posed for this project focused upon the implications of online counselling services for professionals working with young people and young adults in educational settings. The findings provide a helpful insight into the goals that 
individuals have been working to address when accessing online counselling. There are many overlaps with the types of goals raised in face-to-face counselling, and it may be assumed that there is similar potential for supporting young people through such delivery (Department of Health, 2015). As a knock-on effect, this may also support other professionals (such as teaching staff) by reducing some of the emotional labour that is associated with such roles (e.g., Kidger, Gunnell, Biddle, Campbell, \& Donovan, 2009). Such conclusions clearly warrant some caution, as this was not the purpose of the current study; however, flagging the potential of such parallels appears justified. More distinctly, this project highlights two value-added components related to online counselling practices.

1. The potential for services to encourage pupils to be more proactive in their engagement with support services. Students using the online service commonly utilised it as a means to access further support. This observation is in keeping with the view that young people are proactive consumers when seeking support (Gibson \& Cartwright, 2014) and that some individuals may prefer to seek support using the internet (Gray et al., 2005). Further, this may also highlight that accessibility can prove a limitation of face-to-face, school-based services for some individuals. Issues such as the stigma associated with seeking therapeutic support might feed into such a process (e.g., Gulliver, Griffiths, \& Christensen, 2010).

2. The potential to support pupils with issues that they may struggle to bring to a face-to-face service. The list of online goals identifies some nuances that do not appear in the face-to-face list. In particular, the omission of 'interpersonal goals' related to improving intimate relationships provides an insight into the type of goals that do not appear to be articulated in face-to-face counselling with young people. Although, as indicated above, caution is warranted before drawing conclusions, such a dynamic is reflected in previous research (e.g., Hanley, 2012) and therefore adds support to the view that online services can provide complementary elements to face-to-face support.

\section{Strengths, Limitations and Future Directions for Research}

This study provides a unique reflection on the types of goals that students articulate in counselling using different media. It utilises a large pool of routine evaluation data to good effect by using a novel mixed methods design. In doing so, it adds to the literature by providing insights into the help-seeking behaviours of young people and young adults. It is, however, acknowledged that there are complexities related to drawing comparisons between the face-to-face and online samples. For example, controlling for the effects related to different age groups, gender, and the different face-to-face settings was not considered in this piece of work. It is recommended that future work explore how dynamics such as these might have an impact upon the goals that are articulated. Further, adopting an inductive analytical strategy related to the goals means that comparison to other taxonomies proves difficult. This may be viewed as a limitation; however, the practice-based inductive strategy adopted here has led to a number of new ideas coming to the fore without intruding upon the day-to-day workings of the service in question. With this in mind, such 
a strategy might therefore be viewed as harnessing the naturalistic environment to good effect.

Although the project provides empirical support for the different ways in which individuals utilise online and face-to-face counselling services, the quality of the subsequent interventions has not been considered at this stage. To date, evaluation data of such work proves positive (e.g., King, Bambling, Reid et al., 2006); however, further exploration delineated by client-identified goals would be helpful in further assessing the utility of such services for educational establishments. For instance, are the goals that appear to be receiving less attention in face-to-face counselling being addressed effectively online?

\section{Conclusion}

The findings from this project provide a helpful insight into the way that young people used an online counselling service compared to face-to-face services. With this in mind, it is possible to conclude with some confidence that young people utilise online and face-to-face counselling to address different types of therapeutic goals. For instance, in addition to young people working on a wide variety of issues online, they also appear to be utilising online services as a way to access other types of support. The perceived safety within internet-based communication appears to tap into the agentic nature of some young clients and therefore can provide a helpful means to connect with additional support. Additionally, goals focused upon very sensitive issues, such as the exploration of intimate relationships, might be more problematic for young people to broach face to face. It can be suggested, therefore, that online counselling has the potential to provide an important support system for issues that might otherwise remain unexplored. In accounting for distinctions such as those presented within this article, those involved in developing and/or commissioning support systems for young people (whether this be educational establishments or beyond) might wish to weigh up how the value-added nature of a mixed media approach (e.g., face-to-face school-based counselling and online counselling) can be complementary in nature and support young people in addressing a wider array of therapy goals.

\section{References}

Arbor, A., \& Bordin, E.S. (1979). The generalizability of the psychoanalytic concept of the working alliance. Psychotherapy: Theory, Research and Practice, 16, 252-260. http://doi.org/http://dx.doi.org/10.1037/h0085885

Austin, J.T., \& Vancouver, J.B. (1996). Goal constructs in psychology: Structure, process, and content. Psychological Bulletin, 120, 338-375. http://doi.org/10.1037/ 0033-2909.120.3.338

Bambling, M., King, R., Reid, W., \& Wegner, K. (2008). Online counselling: The experience of counsellors providing synchronous single-session counselling to young people. Counselling and Psychotherapy Research, 8, 110-116. http://doi.org/10.1080/14733140802055011

Bohart, A. (2000). The client is the most important common factor: Clients' self-healing capacities and psychotherapy. Journal of Psychotherapy Integration, 10, 127-149. http://doi.org/10.1023/A:1009444132104 
Bond, T. (2004). Ethical guidelines for researching counselling and psychotherapy. Counselling and Psychotheraphy Research, 4, 10-19. http://doi.org/10.1080/ 14733140412331383893

Bradley, J., Murphy, S., Fugard, A., Nolas, S., \& Law, D. (2013). What kind of goals do children and young people set for themselves in therapy? Developing a goals framework using CORC data. Child and Family Clinical Psychology Review, 1, 8-18.

British Psychological Society. (2010). Code of human research ethics. Leicester, UK: BPS Press.

Bugental, J.F.T. (1964). The third force in psychology. Journal of Humanistic Psychology, 4, 19-26. http://doi.org/10.1177/002216786400400102

Callahan, A., \& Inckle, K. (2012). Cybertherapy or psychobabble? A mixed methods study of online emotional support. British Journal of Guidance \& Counselling, 40, 261-278. http://doi.org/10.1080/03069885.2012.681768

Charmaz, K. (2000). Grounded theory: Objectivist and constructivist methods. In N. Denzin \& Y. Lincoln (Eds.), Handbook of qualitative research (2nd ed., pp. 509-535). Thousand Oak, CA: Sage.

Cohen, J. (1992). A power primer. Psychological Bulletin, 112, 155-159. http://doi.org/10.1037/0033-2909.112.1.155

Coleman, J., \& Brooks, F. (2009). Key data on adolescence 2009. Brighton, UK: Association for Young People's Health and Trust for the Study of Adolescence.

Cooper, M. (2013). School-based counselling in UK Secondary Schools: A review and critical evalutation. Glasgow: University of Strathclyde.

Cooper, M. (2015). Existential psychotherapy and counselling: Contributions to a pluralistic practice. London: Sage.

Cooper, M., \& McLeod, J. (2011). Pluralistic counselling and psychotherapy. London: Sage.

Creswell, J.W., Plano Clark, V.L., Gutmann, M., \& Hanson, W. (2003). Advanced mixed methods research designs. In Handbook of mixed methods in social and behavioral research (pp. 209-240). Thousand Oak, CA: Sage.

Department for Education. (2015). Counselling in schools: A blueprint for the future. London: Author. Retrieved from https:/www.gov.uk/government/uploads/ system/uploads/attachment_data/file/416326/Counselling_in_schools_-240315. pdf

Department of Health. (2015). Future in mind: Promoting, protecting and improving our children and young people's mental health and wellbeing. London: NHS England.

Dowling, M., \& Rickwood, D. (2016). Exploring hope and expectations in the youth mental health online counselling environment. Computers in Human Behavior, 55, 62-68. http://doi.org/10.1016/j.chb.2015.08.009

Durlak, J.A., Weissberg, R.P., Dymnicki, A.B., Taylor, R.D., \& Schellinger, K.B. (2011). The impact of enhancing students' social and emotional learning: A metaanalysis of school-based universal interventions. Child Development, 82, 405-432. http://doi.org/10.1111/j.1467-8624.2010.01564.x

Gibson, K., \& Cartwright, C. (2013). Agency in young clients' narratives of counseling: 'It's whatever you want to make of it'. Journal of Counseling Psychology, 60, 340352. http://doi.org/10.1037/a0033110 
Gibson, K., \& Cartwright, C. (2014). Young people's experiences of mobile phone text counselling: Balancing connection and control. Children and Youth Services Review, 43, 96-104. http://doi.org/10.1016/j.childyouth.2014.05.010

Glasheen, K., \& Campbell, M. (2009). The use of online counselling within an Australian secondary school setting: A practitioner's viewpoint. Counselling Psychology Review, 24, 42-51.

Glasheen, K., Campbell, M.A., \& Shochet, I. (2013). Opportunities and challenges: School guidance counsellors' perceptions of counselling students online. Australian Journal of Guidance and Counselling, 23, 222-235. http://doi.org/10.1017/jgc.2013.15

Gray, N.J., Klein, J.D., Noyce, P.R., Sesselberg, T.S., \& Cantrill, J.A. (2005). Health information-seeking behaviour in adolescence: The place of the internet. Social Science \& Medicine, 60, 1467-1478. http://doi.org/10.1016/j.socscimed.2004.08.010

Grosse, M., \& Grawe, K. (2002). Bern Inventory of treatment goals: Part 1 - Development and first application of a taxonomy of treatment goal themes. Psychotherapy Research, 12(1), 79-99. http://doi.org/10.1080/713869618

Gulliver, A., Griffiths, K.M., \& Christensen, H. (2010). Perceived barriers and facilitators to mental health help-seeking in young people: A systematic review. BMC Psychiatry, 10, 113. http://doi.org/10.1186/1471-244X-10-113

Hanley, T. (2006). Developing youth-friendly online counselling services in the United Kingdom: A small scale investigation into the views of practitioners. Counselling and Psychotherapy Research, 6, 182-185. http://doi.org/10.1080/14733140600857535

Hanley, T. (2012). Understanding the online therapeutic alliance through the eyes of adolescent service users. Counselling and Psychotherapy Research, 12, 35-43. http://doi.org/10.1080/14733145.2011.560273

Hanley, T., Jenkins, P., Barlow, A., Humphrey, N., \& Wigelsworth, M. (2013). A scoping review of the access to secondary school counselling. Manchester, UK: University of Manchester.

Hanley, T., Sefi, A., \& Ersahin, Z. (2016). From goals to tasks and methods. In M. Cooper \& W. Dryden (Eds.), The handbook of pluralistic counselling and psychotherapy (pp. 28-41). London: Sage.

Hanley, T., Williams, G., \& Sefi, A. (2013). Pluralistic counselling for young people. In T. Hanley, N. Humphrey, \& C. Lennie (Eds.), Adolescent counselling psychology (pp. 133-156). London: Routledge.

Harris, B. (2013). International school-based counselling. Lutterworth, UK: British Association for Counselling.

Horvath, A.O., Del Re, A. C., Flückiger, C., \& Symonds, D. (2011). Alliance in individual psychotherapy. Psychotherapy, 48, 9-16. http://doi.org/10.1037/ a0022186

Kidger, J., Gunnell, D., Biddle, L., Campbell, R., \& Donovan, J. (2009). Part and parcel of teaching? Secondary school staff's views on supporting student emotional health and well-being. British Educational Research Journal, 36, 919-935. http://doi.org/10.1080/01411920903249308

King, R., Bambling, M., Lloyd, C., Gomurra, R., Smith, S., Reid, W., \& Wegner, K. (2006). Online counselling: The motives and experiences of young people who choose the Internet instead of face to face or telephone counselling. Counselling and Psychotherapy Research, 6, 169-174. http://doi.org/10.1080/ 14733140600848179 
King, R., Bambling, M., Reid, W., \& Thomas, I. (2006). Telephone and online counselling for young people: A naturalistic comparison of session outcome, session impact and therapeutic alliance. Counselling and Psychotherapy Research, 6(3), 175-181. http://doi.org/10.1080/14733140600874084

Krippendorff, K. (2013). Content analysis: An introduction to its methodology (3rd ed.). London: Sage.

Maykut, P., \& Morehouse, R. (1994). Beginning qualitative research. A philosophical and practical guide. London: The Falmer Press.

Pattison, S., Hanley, T., Pykhtina, O., \& Ersahin, Z. (2015). Extending practice: New horizons and contexts. In M. Robson, S. Pattison, \& A. Benyon (Eds.), The Sage handbook for counselling children and young people (pp. 427-441). London: Sage.

Pattison, S., Hanley, T., \& Sefi, A. (2012). Online counseling for children and young people: Using technology to address the Millenium Development Goals in Kenya. In B. Popoola \& O. Adebowale (Eds.), Online guidance and counseling: Toward effectively applying technology (pp. 135-151). IGI Global: Hershey. http://doi.org/10.4018/978-1-61350-204-4

Rennie, D., \& Fergus, K. (2006). Embodied categorizing in the grounded theory method: Methodical hermeneutics in action. Theory \& Psychology, 16, 483-503. http://doi.org/10.1177/0959354306066202

Rennie, D.L., Phillips, J.R., \& Quartaro, G.K. (1988). Grounded theory: A promising approach to conceptualization in psychology? Canadian Psychology/Psychologie Canadienne, 29, 139-150. http://doi.org/10.1037/h0079765

Rupani, P., Cooper, M., McArthur, K., Pybis, J., Cromarty, K., Hill, A., ... Turner, N. (2013). The goals of young people in school-based counselling and their achievement of these goals. Counselling and Psychotherapy Research, 14, 306-314. http://doi.org/10.1080/14733145.2013.816758

Rupani, P., Haughey, N., \& Cooper, M. (2012). The impact of school-based counselling on young people's capacity to study and learn. British Journal of Guidance \& Counselling, 40, 499-514. http://doi.org/10.1080/03069885.2012.718733

Sefi, A., \& Hanley, T. (2012). Examining the complexities of measuring effectiveness of online counselling for young people using routine evaluation data. Pastoral Care in Education, 30, 49-64. http://doi.org/10.1080/02643944.2011.651224

Shirk, S.R., Karver, M.S., \& Brown, R. (2011). The alliance in child and adolescent psychotherapy. Psychotherapy, 48, 17-24. http://doi.org/10.1037/a0022181

Strauss, A., \& Corbin, J. (1998). Basics of qualitative research: Techniques and procedures for developing grounded theory (2nd ed.). London: Sage.

Suler, J. (2004). The online disinhibition effect. Cyberpsychology \& Behavior: The Impact of the Internet, Multimedia and Virtual Reality on Behavior and Society, 7, 321-6. http://doi.org/10.1089/1094931041291295

Tryon, G.S., \& Winograd, G. (2011). Goal consensus and collaboration. Psychotherapy, 48, 50-57. http://doi.org/10.1037/a0022061

Vossler, A., \& Hanley, T. (2010). Online counselling for young people - Meeting the needs of young people in late modern society. In J. Leaman \& M. Worsching (Eds.), Youth in contemporary Europe (pp. 133-150). London: Routledge.

Wolak, J., Mitchell, K.J., \& Finkelhor, D. (2003). Escaping or connecting? Characteristics of youth who form close online relationships. Journal of Adolescence, 26, 105-119. http://doi.org/10.1016/S0140-1971(02)00114-8 
Terry Hanley

\section{Appendix}

The Counselling Goal System (CoGS)

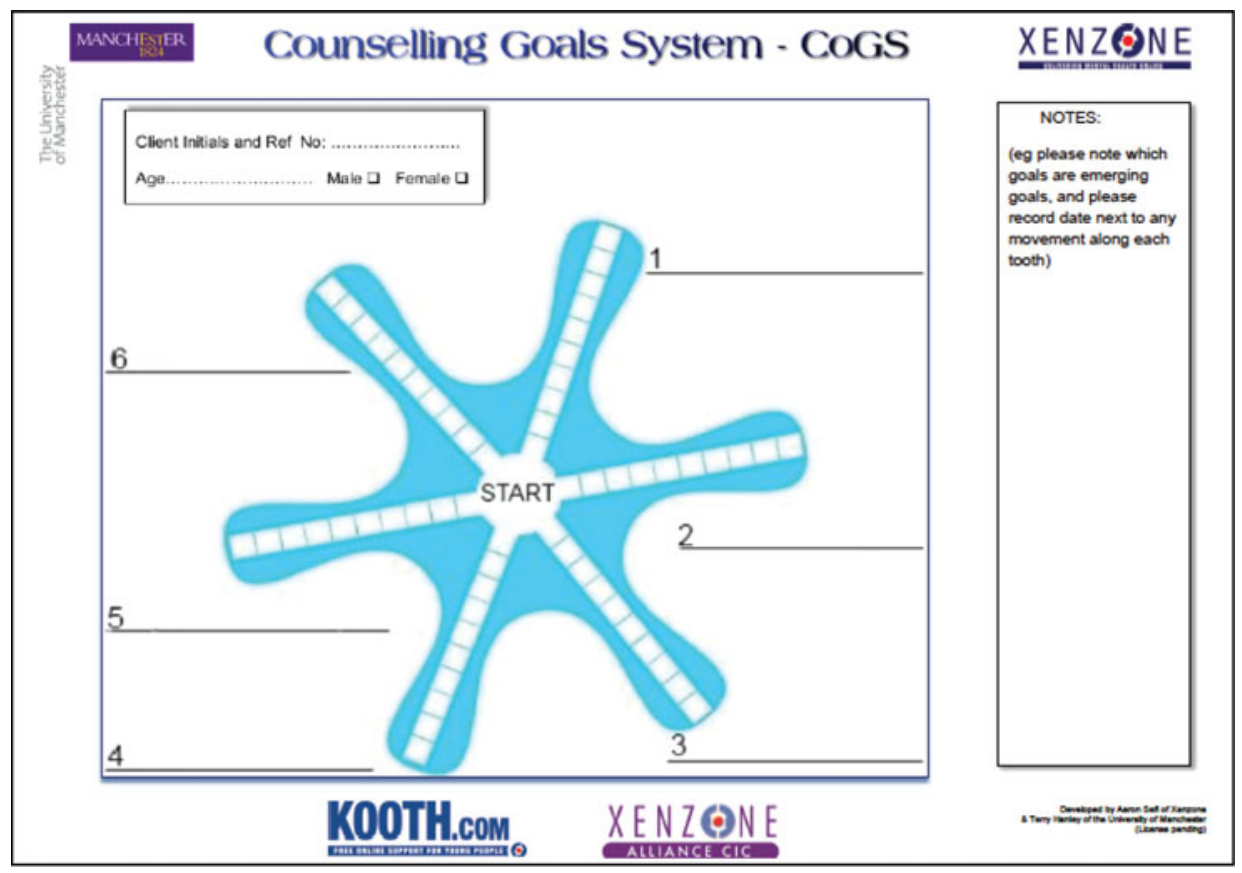

54 Journal of Psychologists and Counsellors in Schools 